\title{
Maria Junqueira Schmidt: uma intelectual católica em diálogo com a Escola Nova
}

\author{
Maria Junqueira Schmidt: a catholic intellectual in \\ dialogue with the New School
}

EVELYN DE ALMEIDA ORLANDO (iD

\section{Resumo}

Este artigo aborda a trajetória da educadora Maria Junqueira Schmidt, como uma intelectual católica e forte defensora da pedagogia nova alinhada ao catolicismo. Suas ações dão a ver modos de apropriação dos enunciados da Escola Nova a partir de suas experiências de formação na Europa quanto nos EUA, introduzidas no Brasil no ensino de línguas vivas, designadamente no ensino de francês. Notícias de jornais e relatórios de viagens, publicados na imprensa periódica, foram as principais fontes mobilizados nesta pesquisa, indicativas dos modos de apropriação da referida educadora. Pode-se dizer que, a partir da militância como intelectual e educadora católica, Maria Junqueira Schmidt inseriu-se e afirmou-se no campo da produção intelectual do país, tendo a educação como seu lugar privilegiado de fala.

Palavras-chave: Mulheres intelectuais. Escolanova católica. Militância feminina.

\section{Abstract}

This article addresses the trajectory of educator Maria Junqueira Schmidt, as a Catholic intellectual and strong advocate of new pedagogy aligned with Catholicism. Her actions show ways of appropriating the enunciations of the New School from her training experiences in Europe as well as in the USA, introduced in Brazil in the teaching of living languages, namely French. Newspaper news and travel reports, published in the periodic press, were the main sources mobilized in this research, indicative of the ways of appropriation of the referred educator. It can be said that,

a Pontifício Universidade Católica do Paraná/PUC/PR, Curitiba, Paraná, Brasil. Doutora em Educação, e-mail: evelynorlando@gmail.com

72

Rev. Caminhos da Educação: diálogos, culturas e diversidades, Teresina, v. 2, n. 3, p. 72-91, set./dez. 2020 
Maria Junqueira Schmidt: uma intelectual católica em diálogo com a Escola Nova

from her militancy as an intellectual and Catholic educator, Maria Junqueira Schmidt has inserted herself and asserted herself in the field of the country's intellectual production, having education as her privileged place of speech.

Keywords: Intellectual women. Catholic Schmidt. Women's militancy.

\section{Resumen}

Cet article traite de la trajectoire de l'éducatrice Maria Junqueira Schmidt, en tant qu'intellectuelle catholique et ardente défenseuse d'une nouvelle pédagogie alignée sur le catholicisme. Ses actions montrent comment s'approprier les énonciations de la Nouvelle Ecole à partir de ses expériences de formation en Europe ainsi qu'aux USA, introduites au Brésil dans l'enseignement des langues vivantes, à savoir le français. Les informations de presse et les récits de voyage, publiés dans la presse périodique, ont été les principales sources mobilisées dans cette recherche, révélatrices des modes d'appropriation dudit éducateur. On peut dire que, dès son militantisme en tant qu'intellectuelle et éducatrice catholique, Maria Junqueira Schmidt s'est insérée et s'est affirmée dans le domaine de la production intellectuelle du pays, ayant l'éducation comme lieu privilégié de parole.

Mots-clés : Femmes intellectuelles. L’École Nouvelle catholique. Le militantisme des femmes.

\section{Introdução}

Maria Junqueira Schmidt foi uma educadora e intelectual católica que militou pela pátria, pelo catolicismo e pela Educação Nova no Brasil ${ }^{1}$ entre os anos de 1920 e 1980. Como educadora, sempre buscou aplicar os princípios da Pedagogia e da Psicologia que aprendeu em sua trajetória. Apesar de seu lócus privilegiado de

\footnotetext{
${ }^{1}$ O movimento da Escola Nova no Brasil esteve longe de ser monolítico e abraçou muitas vertentes de educadores que buscavam o diálogo com as Ciências da Educação. Deste modo, os termos educação nova assim como escola nova ou escola ativa conviveram de modo muito imbricado nos debates e projetos em prol da renovação escolar no Brasil. Esses dois últimos eram praticamente sinônimos a partir dos anos de 1920, mas a noção de escola ativa também se misturava a de escola moderna, sobretudo nas apropriações católicas, as quais fizeram as duas coexistir ao mesmo tempo em muitas de suas propostas. As ideias da educação nova foram aplicadas à escola, mas também a outros domínios relacionados à educação, tais como o catecismo, os movimentos associativos como o escotismo, entre outros.

Rev. Caminhos da Educação: diálogos, culturas e diversidades, Teresina, v. 2, n. 3, p. 72-91, set./dez. 2020
} 
trabalho ter sido o Rio de Janeiro, suas ações se estenderam por todo o território nacional por meio de livros, cursos, conferências e programas de rádio e TV22.

Filha de uma família da elite paulistana, Maria Junqueira Schmidt, de origem suíça, nasceu em São Paulo, em 20 de setembro de 1900, onde viveu até os 11 anos. Depois de estudar seis anos no Brasil, na Adalberto Schuele, dirigida por religiosas alemãs, ela prosseguiu sua formação escolar durante os dez anos seguintes na Europa. Primeiro, estudou na Mittelschule em Munster, na Westphalia; dali seguiu para a Bélgica, onde estudou no colégio Zildonck, mantido pelas ursulinas. Depois de ter obtido o diploma de habilitação para o ensino na École Normale Sainte-Ursule, à Fribourg, en Suisse, ela se dedicou aos estudos de Pedagogia e de Psicologia na Université de Fribourg. En 1920, Maria Junqueira Schmidt retornou ao Brasil em razão do estado de saúde de seu pai, antes de concluir seu percurso universitário, mas após ter prolongado sua experiência de viagem em uma estadia na Itália e na França. ${ }^{3}$.

0 retorno de Maria Junqueira ao Brasil foi noticiado com pompa e exaustivamente nos jornais do Rio de Janeiro - então, capital da República Federativa do Brasil (ou Distrito federal) - e São Paulo, os quais funcionaram como veículos de apresentação à sociedade para a recém-chegada educadora. Além de notícias como a que reproduzimos a seguir, suas conferências, no início de sua carreira, eram também publicadas na íntegra nos principais jornais da cidade.

\section{LEITURAS E CONFERÊNCIAS}

SALÃO DO CONSERVATÓRIO: “CONFERÊNCIA PEDAGÓGICA" PELA SENHORITA MARIA JUNQUEIRA SCHMIDT

[...] Tratando de pedagogia que é a sciência do método, a conferência agradou principalmente pelo metódico e bem ordenado da exposição, muito límpida e muito segura. Em primeiro lugar as generalidades do método, depois o esboço da instrução pública na Suissa e por fim o plano de ensino que adotou, o trabalho da senhorita

\footnotetext{
${ }^{2}$ Sobre Maria Junqueira Schmidt, ver Orlando (2015, 2017a, 2017b) e a dissertação de mestrado de Skruzinski (2018), orientada por Orlando.

3 "Maria Junqueira Schmidt", Diário de Notícias, Rio de Janeiro, 8 avril 1934, p. 21.

Rev. Caminhos da Educação: diálogos, culturas e diversidades, Teresina, v. 1, n. 3, p. XXX-XXX, set./dez. 2019
} 
Junqueira interessou a toda a sala, revelando sólidos conhecimentos.

Em suma, a conferencista propõe-se a fazer nesta capital uma série de cursos superiores do ensino, empregando os seus métodos, sob a forma de conferencias. A geografia e a história serão tratadas conjuntamente, com referencias à geologia, à antropologia, e ciências anexas. A pedagogia será encarada em suas relações com a Filosofia e a Psicologia. A literatura será também versada sob um aspecto original de maneira a produzir o melhor resultado com o maior prazer.

Como se vê, a iniciativa da senhorita Junqueira Schmidt é interessante e merecedora da atenção de nossas classes cultas. ${ }^{4}$

O Diário de Notícias, do Rio de Janeiro, a fez figurar em 1934, na seção "Registro da Mulher Moderna", na qual destinou quase uma página inteira do periódico para apresentar a seus leitores a conceituada pedagoga. A referência a sua formação na Europa e o contato com o que havia de mais novo na nova pedagogia era o aspecto mais distintivo ${ }^{5}$ ressaltado em sua biografia que, reforçado por sua sólida e importante rede de sociabilidade ${ }^{6}$, lhe serviu como dispositivo de autoridade no campo educacional brasileiro.

Uma autora de livros didáticos e educacionais

Suas primeiras obras de fôlego são relacionadas à História, mais especificamente, biografias históricas de mulheres da nobreza brasileira, seguidas do livro História do Brasil, publicado em 1931, com o qual colabora com o renomado

\footnotetext{
4 "Leituras e conferências - Salão do conservatório: "Conferência pedagógica" pela senhorita Maria Junqueira Schmidt”. O Estado de São Paulo, 2 décembre 1920, p. 10.

${ }^{5}$ Neste trabalho, utilizamos o conceito de distinção na perspectiva de Pierre Bourdieu (2007).

${ }^{6} \mathrm{O}$ conceito de rede de sociabilidade é mobilizado aqui tal como propõe Jean-François Sirinelli (1996). Rev. Caminhos da Educação: diálogos, culturas e diversidades, Teresina, v. 2, n. 3, p. 
intelectual católico Jônathas Serrano ${ }^{7}$. Essa parceria pode ser considerada como um dos primeiros passos de Maria Junqueira Schmidt na produção de livros didáticos em diálogo com os pressupostos escolanovistas. Essa orientação pedagógica que assumirá em sua produção intelectual pode ser associada a três fatores: a formação que recebeu na Suíça; a entrada nos debates acerca da renovação do campo educacional brasileiro; e a influência que recebeu da ala mais progressista do campo intelectual católico em relação à Pedagogia.

A partir dos anos de 1930, sua produção muda o foco e passa a centrar-se, fundamentalmente, em livros voltados para a área da educação e ensino de francês. Desse conjunto expressivo, empreendido pela autora, - um conjunto de trinta e sete obras - , podemos perceber três nichos de produção que podem ser lidos como frentes de atuação e de intervenção política na sociedade brasileira, considerando sua condição de mulher ligada ao grupo dos intelectuais católicos: Literatura, História e Educação. Este último eixo compreende manuais pedagógicos, livros escolares e livros endereçados à educação das famílias, arrolados no quadro a seguir:

Quadro 1: Títulos publicados por Maria Junqueira Schmidt

\begin{tabular}{|l|l|l|}
\hline \multicolumn{1}{|c|}{ TÍTULO } & \multicolumn{1}{|c|}{ EDITORA } & \multicolumn{1}{|c|}{ ANO } \\
\hline Entre a vida e o sonho (contos) & \multicolumn{1}{|c|}{} & 1925 \\
\hline $\begin{array}{l}\text { A segunda imperatriz do Brasil - Amélia } \\
\text { de Leuchtenberg (biografia laureada pela } \\
\text { Academia de Letras) }\end{array}$ & Ed. Melhoramentos & 1927 \\
\hline $\begin{array}{l}\text { História do Brasil } \\
\text { Jônathas Serrano } \\
\text { (colaboração de Maria Junqueira Schmidt } \\
\text { e colaboração de D. Helena S. de } \\
\text { Medeiros }\end{array}$ & Briguiet & 1931 \\
\hline $\begin{array}{l}\text { Francês, } 1^{\circ} \text { ano. } \\
\text { Princesa Maria da Glória }\end{array}$ & $\begin{array}{l}\text { Companhia Editora } \\
\text { Nacional (CEN) }\end{array}$ & 1933 \\
\hline
\end{tabular}

\footnotetext{
${ }^{7}$ Esta obra merece atenção por fazer parte das primeiras produções históricas da autora, mas sobretudo por ter sido sua primeira inserção no campo dos livros didáticos. Publicada apenas em 1931, segundo Giovane Silva (2011), o livro vinha sendo escrito desde 1926. Neste ano, Jonathas Serrano recebeu uma proposta de publicação e apresentou à colega Maria Junqueira Schmidt (ela era diretora da Academia Feminina, no Rio de Janeiro, instituição que oferecia um curso superior em dois anos de formação para o ensino e onde Jonathas Serrano era professor). Ela, então, se encarregou do trabalho junto com ele, conforme o próprio explica na apresentação da obra História do Brasil (1931). Sobre o livro e a presença católica na produção historiográfica do país, ver também o trabalho de Freitas (2008).

Rev. Caminhos da Educação: diálogos, culturas e diversidades, Teresina, v. 1, n. 3, p. xxx-xxx, set./dez. 2019
} 
Maria Junqueira Schmidt: uma intelectual católica em diálogo com a Escola Nova

\begin{tabular}{|c|c|c|}
\hline TÍTULO & EDITORA & ANO \\
\hline Heures Joyeuse & CEN & 1934 \\
\hline Mon Petit Univers & CEN & 1934 \\
\hline $\begin{array}{l}\text { E Ensino } \\
\text { Modernas }\end{array}$ & Briguiet & 1935 \\
\hline $\begin{array}{l}\text { My little world vitalized method estágio } \\
\text { intermediário entre o método direto e o } \\
\text { método científico }\end{array}$ & $\begin{array}{ll}\text { Companhia } & \text { Editora } \\
\text { Nacional } & \end{array}$ & 1935 \\
\hline $\begin{array}{l}\text { La France }\left(3^{\circ} \text { ano de francês) [3ème }\right. \\
\text { année de français] }\end{array}$ & CEN & 1937 \\
\hline Cours de Français (1ère année) & CEN & $1943(?)$ \\
\hline Cours de Français (2ème année) & CEN & $1943(?)$ \\
\hline Cours de Français (3ème et 4ème années) & CEN & 1943 \\
\hline Les plus belles histoires & Americ & 1943 \\
\hline Cours de Français (3 ème année) & CEN & 1944 \\
\hline Cours de Français (4ème année) & CEN & 1944 \\
\hline $\begin{array}{l}\text { La Littérature Française: Curso Clássico e } \\
\text { Científico- } 1^{\circ} \text { e } 2^{o} \text { ano [Cours classique et } \\
\text { scientifique }-1^{\text {ère }} \text { et } 2^{\text {ème }} \text { année du } \\
\text { collégial }^{8} \text { ] }\end{array}$ & CEN & 1944 \\
\hline $\begin{array}{l}\text { Français Commercial, curso comercial- } \\
\text { básico, 1a ano }\end{array}$ & CEN & 1950 \\
\hline $\begin{array}{l}\text { Français Commercial, curso comercial- } \\
\text { básico, } 2^{o} \text { ano [cours commercial de base } \\
1^{\text {ère année] }}\end{array}$ & CEN & 1951 \\
\hline $\begin{array}{l}\text { La litterature française (de acôrdo com os } \\
\text { novos programas, conforme Portaria n. } \\
966 \text {, de 2-10-51 e n. } 1.045 \text { de 14-12-51.) } \\
\text { Para os cursos clássicos e cientificos }\end{array}$ & CEN & 1952 \\
\hline $\begin{array}{l}\text { Français Commercial, } 3^{o} \text { e } 4^{o} \text { anos do } \\
\text { curso comercial-básico }\end{array}$ & CEN & 1954 \\
\hline $\begin{array}{l}\text { Orientação educacional e educação } \\
\text { sexual: Conferência pronunciada no curso } \\
\text { de Orientação Educacional do Colégio do } \\
\text { Ar-Rádio MEC }\end{array}$ & C.A.D.E.S./MEC & 1954 \\
\hline $\begin{array}{l}\text { Pequeno dicionário Francês - Português } \\
\text { Coautoria com Marina Delamare }\end{array}$ & CEN & 1957 \\
\hline
\end{tabular}

\footnotetext{
${ }^{8}$ Le colegial en portugais, traduit ici par collégial, est l'équivalent du lycée en France.

Rev. Caminhos da Educação: diálogos, culturas e diversidades, Teresina, v. 2, n. 3, p. 


\begin{tabular}{|l|l|l|}
\hline \multicolumn{1}{|c|}{ TÍTULO } & \multicolumn{1}{|c|}{ EDITORA } & ANO \\
\hline Educar pela recreação & Agir & $\begin{array}{l}1958, \\
1967\end{array}$ \\
\hline Le Français & CEN & 1959 \\
\hline $\begin{array}{l}\text { O adolescente na escola: Conferência } \\
\text { proferida no "Encontro de Educadores", de } \\
\text { Belo Horizonte }\end{array}$ & C.A.D.E.S./MEC & 1959 \\
\hline $\begin{array}{l}\text { O adolescente na escola: Conferência } \\
\text { proferida no "Encontro de Educadores", de } \\
\text { Belo Horizonte }\end{array}$ & CADES/MEC & \\
\hline $\begin{array}{l}\text { A Orientação educacional dos } \\
\text { adolescentes: Conferência pronunciada no } \\
\text { curso de Orientação Educacional do } \\
\text { Colégio do Ar - Rádio MEC }\end{array}$ & CADES/ MEC & 1959 \\
\hline Educar para a responsabilidade & Agir & 1960 \\
\hline Também os pais vão à escola... & Agir & 1961 \\
\hline $\begin{array}{l}\text { Orientação Educacional } \\
\text { Coautoria com Maria de Lourdes de } \\
\text { Souza Pereira }\end{array}$ & Agir & 1962 \\
\hline Associação de Pais e Professores & C.A.D.E.S/MEC & 1963 \\
\hline A família por dentro & Agir & 1965 \\
\hline Deus em casa & Agir & 1965 \\
\hline $\begin{array}{l}\text { Vivência para a cidadania } \\
\text { Curso de Educação Moral e Cívica 3v. }\end{array}$ & MEC & 1967 \\
\hline
\end{tabular}

Fonte: Organizado pela autora com base nos anúncios publicados na imprensa periódica do período de 1927 a 1970 referentes aos lançamentos dos livros, destacadamente os jornais Diário de Notícias, Gazeta do Povo, Jornal do Brasil e o Estado de São Paulo, no IHGB e em alguns exemplares localizados em bibliotecas e sebos.

É importante destacar que Maria Junqueira Schmidt soube ao longo de sua carreira estabelecer relações com os poderes públicos e as instâncias as quais definiam as políticas educativas em nível nacional. Nesse sentido, é digno de nota sua participação sucessiva em quatro comissões estratégicas: A Comissão de Literatura Infantil do Ministério da Educação presidida pelo Ministro Gustavo Capanema, em $1936^{9}$, na qual participava igualmente Cecília Meireles ; a Comissão do Livro Didático instituída por decreto do l'Estado Novo ${ }^{10}$ de Getúlio Vargas em 1938, da qual participava também Sérgio Buarque de Holanda ${ }^{11}$; a Comissão

\footnotetext{
9 "Livros bons para as crianças - A primeira reunião, hontem, da Commissão de Literatura Infantil, no Ministerio da Educação". Diário de Notícias, Rio de Janeiro, $1^{\text {er }}$ mai 1936, p. 2.

${ }^{10}$ Regime politique da ditadura instaurada por Getúlio Vargas, em vigor no Brasil de 1937 à 1945.

11 "Designada uma commissão para compra de livros escolares". Diário de Notícias, Rio de Janeiro, 14 agosto de 1938, p. 2.

Rev. Caminhos da Educação: diálogos, culturas e diversidades, Teresina, v. 1, n. 3, p. XXX-XXX, set./dez. 2019
} 
Maria Junqueira Schmidt: uma intelectual católica em diálogo com a Escola Nova

encarregada da elaboração dos Programas dos Cursos de Ginásio da Reforma Capanema ${ }^{12}$ em 1942 e, em 1947, a Comissão encarregada de discutir a Lei de Diretrizes e Bases da Educação Nacional para o Ensino Secundário ${ }^{13}$. A participação de Maria Junqueira Schmidt nessas comissões ligadas à Reforma Capanema revela a articulação política desta intelectual e a participação do laicato católico na esfera do Estado.

A reforma empreendida por Gustavo Capanema em 1942 - conhecida pelo nome de «Leis Orgânicas do Ensino - constitui a primeira política nacional que visava estruturar a educação no Brasil em todos os níveis (até o secundário) e em todos os segmentos de ensino (geral e técnico-profissional).

\begin{abstract}
Além de instituir o ensino profissional e a orientação educacional, ela redefiniu o ensino secundário, que consistia agora de um ginásio de 4 anos e colegial de 3 anos dividido em ensino clássico e científico. [...] No ginásio, o latim, francês e inglês eram matérias obrigatórias, com quatro anos de ensino para as duas primeiras, e três para a terceira. No colegial, um ano era consagrado ao ensino do francês e dpois anos estavam reservados ao inglês e aos espanhol, e na opção clássica, o aluno tinha outros três anos de latim e de grego. 0 número de horas consagradas às línguas vivas atingia quase $20 \%$ do tempo total do programa de estudos. ${ }^{14}$
\end{abstract}

\footnotetext{
12 "Para organização dos programas do curso ginasial - Uma portaria do ministro da Educação estabelecendo normas para os trabalhos da comissão encarregada". Diário de Notícias, Rio de Janeiro, 28 abril 1942, p. 6.

13 "Instituída a comissão de estudo das diretrizes e bases da educação". Diário de Notícias, Rio de Janeiro, 8 abril de 1947, p. 6.

${ }^{14}$ PIETRARÓIA, Cristina M. C., Dellatorre, Sahsha K. W. O ensino do francês no Brasil. Odisseia, Natal, RN, n. 09, p. 97-124, jul.-dez. 2012, p. 113-114.

Rev. Caminhos da Educação: diálogos, culturas e diversidades, Teresina, v. 2, n. 3, p. 72-91, set./dez. 2020
} 
A partir do pós-guerra e, sobretudo, a partir do período da ditadura civilmilitar no Brasil (1964-1985), o francês perdeu seu prestígio no sistema educativo e, em virtude dos acordos estabelecidos com os Estados Unidos, a aprendizagem do inglês se se tornou cada vez mais imperativa. A língua inglesa se impôs a partir do momento em que a LDB (Lei de Diretrizes e Bases da Educação) de 1961 suprimiu a obrigação de ensinar uma língua estrangeira no secundário, a opção por sua inclusão nos programas escolares cabia a cada um dos Estados da Federação. A partir de então, a opção - quando ela era feita - era pelo inglês. Essas mudanças nos programas escolares explicam a concentração da produção de livros didáticos de francês pela autora, até os anos de 1960, para todos os níveis do ginásio e do colegial, quando o francês era uma matéria obrigatória.

Entre os anos de 1950 e 1970, sua produção se voltou para os temas da educação familiar e da orientação educacional, os quais encontravam apoio nos argumentos e valores defendidos pelos setores mais conservadores da sociedade brasileira. 0 primeiro tema encontrava alinhamento com os valores defendidos por movimentos como a Marcha da Família com Deus pela Liberdade ${ }^{15}$, e o segundo visava à adaptação da juventude às necessidades sociais.

Nos anos de 1970, ela continuou a se dedicar à redação de manuais escolares, publicando um conjunto de livros sobre educação moral e cívica. Seu alinhamento sobre os temas em voga mostram, ainda que de maneira indiciária, uma posição política e uma concepção de sociedade. Ele mostra igualmente a maneira pela qual ela participou do campo intelectual e se manteve em diferentes postos relacionados do poder ao longo de sua trajetória profissional. Esta estratégia de se manter no campo da produção de livros escolares e pedagógicos foi adotada por uma parte significativa dos intelectuais que defenderam a renovação do ensino no Brasil. Qualquer que seja o grupo ao qual eles pertenciam, os militantes da Escola Nova no Brasil investiram na utilização de textos impressos para moldar o campo pedagógico

\footnotetext{
${ }^{15}$ A Marcha da Familia com Deus pela Liberdade foi um movimento de manifestações nas ruas de caráter conservador, anti-comunista, organizado em 1964 no Brasil pelas mulheres católicas ligadas à Camde (Campanha da Mulher pela Democracia), as quais defenderam e apoiaram o golpe civil-militar. Cf LAMARÃO, Sérgio. A Marcha da Família com Deus pela Liberdade, in A trajetória política de João Goulart, FGV-CPDOC. Disponível no link: ttps://cpdoc.fgv.br/producao/dossies/Jango/artigos/AConjunturaRadicalizacao/A_marcha_da_familia_co m_Deus (acesso 18 julho de 2020).

Rev. Caminhos da Educação: diálogos, culturas e diversidades, Teresina, v. 1, n. 3, p. XXX-XXX, set./dez. 2019
} 
Maria Junqueira Schmidt: uma intelectual católica em diálogo com a Escola Nova

e ocuparam espaço não apenas na esfera da produção, mas também na mediação de saberes educacionais, propagando os diferentes projetos de nação em disputa na sociedade brasileira.

Não obstante a diversidade de sua produção, Maria Junqueira Schmidt se destacou como autora de manuais escolares e manteve-se nesse lugar por quatro décadas. Seus livros foram reeditados diversas vezes, alguns chegaram a mais de cinquenta edições. O lugar privilegiado que ela ocupou nas diversas comissões, notadamente na Comissão Nacional do Livro Didático, certamente a favoreceu neste empreendimento, mas ter inserido a pedagogia da Escola Nova no ensino secundário, em particular no ensino de línguas vivas, sem dúvida, foi um elemento diferencial em sua careira.

Uma militante da escola nova católica

Entre os anos 1920 a 1930, os debates sobre a Escola Nova, em particular o diálogo com a Psicologia, foram intensificados no Brasil. Apesar das disputas políticas em torno do campo da educação, notadamente no que concerne à laicidade e à coeducação nas escolas, no domínio pedagógico, a apropriação dos pressupostos das Ciências da Educação, notadamente da Psicologia e da Biologia, era objeto de consenso. A entrada das mulheres nesse espaço e nesse debate foi igualmente intensificada nessa época com uma participação acentuada no ensino primário.

A atuação de Maria Junqueira no Ensino Secundário como professora e gestora de uma escola pública, profissional e mista abriu os horizontes para outros espaços e formas de atuação das mulheres na disputa que se travou pelo campo educacional. A apropriação dos pressupostos da Escola Ativa para esse segmento de ensino, como autora de manuais, marcou sua entrada e legitimação no campo da 
produção intelectual do país como militante do que estamos chamando de Escola Nova católica ${ }^{16}$.

O papel exercido por Maria Junqueira Schmidt no ensino secundário como professora e diretora de uma escola pública, profissional e mista abriu um horizonte na direção de outros espaços e formas de ação para as mulheres nas disputas que se desenvolveram no campo da educação nesse período. Sua apropriação dos postulados da Esola Ativa para esse esse segmento da educação, como autora de manuais escolares, marcaram sua entrada e sua legitimação no campo da produção intelectual doo país como militante do que chamamos de Escola Nova Católica ${ }^{17}$.

Desde seu retorno ao Brasil, em suas conferências pedagógicas, a educadora deixou claro sua inclinação para a "pedagogia moderna". Sem fazer menção a nenhum autor de forma recorrente, ela cita diferentes experiências exitosas em países como Suíça, Alemanha e Bélgica e alguns precursores da escola Nova, tais como Wilhelm August Lay e Paul Geheeb. Elle n'est jamais entrée directement sur le plan discursif dans la polémique de la mixité à l'école à cette époque, mais elle a pris la direction d'une école publique mixte.

Em um jogo de luzes e sombras discursivas, essas pistas compõem um mosaico de sua concepção pedagógica. De início, suas apresentações enfocam a interdisciplinaridade e a necessidade de que a aprendizagem seja associada ao prazer e à atividade. Em suas primeiras conferências, os saberes e o que enquadramos como disciplinas escolares eram apresentados sempre em movimento e em relação uns com os outros como visto na citação feita na primeira parte deste texto. A emancipação da mulher pela educação era um tema recorrente em seus discursos, assim como os trabalhos manuais para os estudantes. E embora nunca tenha entrado diretamente, no âmbito discursivo, na polêmica da coeducação, assumiu a direção de uma escola pública profissional mista.

Em 1925, em texto publicado no jornal A.B.C., a educadora sinalizava uma aproximação com a corrente pedagógica Suíça, lugar privilegiado de sua formação.

\footnotetext{
${ }^{16}$ Sobre Escola Nova Católica, ver a tese de Sgarbi (1997), as dissertações de mestrado de Orlando (2008), Skalinski Junior (2015), Prachum (2019) e o dossiê organizado por Norberto Dallabrida e José Eduardo Franco (2018).

${ }^{17}$ Sobre a Escola Nova católica, ver a tese de doutorado de Skalinski Junior (2015), as dissertações de Mestrado de Sgarbi (1997), Orlando (2008), e Prachum (2019), e o dossiê organizado por Norberto Dallabrida e José Eduardo Franco (2018).

Rev. Caminhos da Educação: diálogos, culturas e diversidades, Teresina, v. 1, n. 3, p. XXX-XXX, set./dez. 2019
} 
Maria Junqueira Schmidt: uma intelectual católica em diálogo com a Escola Nova

Ao comentar uma viagem feita por outra intelectual e educadora católica - Laura Jacobina Lacombe -, Maria Junqueira argumentava em prol da necessidade dessa renovação. Nessa ocasião, ressaltou a importância do Instituto Jean-Jacques Rousseau, de Genebra, como uma das mais célebres instituições em matéria de educação e ciência na Europa.

Basta dizer que suas cathedras são occupadas por mestres insignes como Bovet, Claparéde e Ferrière, cuja competência profissional e dedicação à mocidade não encontram rivaes em nossos. Pouco importa que essas notabilidades sejam protestantes e que protestante seja também o instituto: - a sciencia é patrimonio universal, é bem da humanidade. Si não houver quem se incumba de haurir nos campos adversos os ensinamentos da sciencia para depois traze-los aos arraes catholicos viveremos nós, os catholicos, num plano inferir, como que enclausurados, muitas vezes alheios às descobertas feitas pelos inimigos da religião".18

A pedagogia da Escola Ativa aplicada ao ensino de línguas vivas

Mas é no final dos anos de 1920 que sua militância pela Escola Ativa ganhou forma e materializou-se uma proposição original. Em razão de um concurso público para professora de francês na Escola de Comércio Amaro Cavalcanti, ela defendeu o que apresentou como método para o ensino de línguas estrangeiras, com base no que havia de mais novo no âmbito pedagógico para a disciplina e nesse segmento de ensino. A submissão a uma banca de concurso significava, em caso de aprovação, a legitimação de seus pares e a chance de inserir uma marca própria no campo. Depois

\footnotetext{
${ }^{18}$ Ver SCHMIDT, Maria Junqueira. A educação da criança na palavra de uma conferencista. Jornal A.B.C., Rio de Janeiro, 18 juillet 1925, p. 9.

Rev. Caminhos da Educação: diálogos, culturas e diversidades, Teresina, v. 2, n. 3, p. 72-91, set./dez. 2020
} 
do êxito no concurso, Maria Junqueira, afirmando na imprensa seu ineditismo na temática e projetando-se para além do grupo de intelectuais por onde já circulava, publicou uma síntese de seu método no Jornal do Commércio:

A pedagogia moderna já delineou, em traços precisos, os moldes da methodologia no que concerne ao ensino infantil, isto é, aos cursos primários. O Brasil pode ufanar-se de estar na vanguarda dos raros paízes, que, de início adoptaram officialmente, a reforma pedagógica cujos resultados têm sido surprehendentes na Bélgica, na Suissa e na Allemanha. A aplicação dos princípios da escola ativa ao curso secundário tem sido mais lenta e laboriosa, conquanto segura e de extraordinária efficiência. Nada, porém, absolutamente nada se tem feito a respeito do ensino das línguas estrangeiras. A própria "Revue de l'Enseignement des Langues Vivantes" pouco preconiza além do método directo. Em 1928, por ocasião de um concurso de francez, tive a opportunidade de offerecer ao exame e à crítica dos doutos um processo original para o ensino das línguas vivas. A experiência do magistério e a continuidade da observação habilitam-me a asseverar que o aproveitamento dos alumnos corresponde em tudo e por tudo ao esforço, que acaso o novo methodo possa exigir do professor. ${ }^{19}$

O novo método consistia, segundo a educadora, em observar e estimular os seguintes elementos: a atividade espontânea da criança como ponto fundamental de partida, suas habilidades manuais e construtivas, suas inclinações e energia mental, suas afeições e interesses. A fala, tendência inata da criança, era considerada central para o aprendizado de línguas em consonância com a necessidade que a criança apresenta de falar como um princípio preconizado pelos pioneiros da escola activa, qual seja: "partir das necessidades primordiais do homem com o objetivo de atingir 'um fim útil'”20, citando Lay e Geheeb e deixando novas pistas sobre um possível alinhamento à corrente pedagógica escolanovista europeia, de matriz alemã e Suíça.

\footnotetext{
${ }^{19}$ Cf. SCHMIDT, Maria Junqueira. ESCOLA ACTIVA. Metodo novo para o ensino das línguas vivas. Correio da Manhã, 19 juillet 1929, p. 7.

${ }^{20}$ Idem.

Rev. Caminhos da Educação: diálogos, culturas e diversidades, Teresina, v. 1, n. 3, p. XXX-XXX, set./dez. 2019
} 
Maria Junqueira Schmidt: uma intelectual católica em diálogo com a Escola Nova

Uma vez aprovada no concurso, Maria Junqueira Schmidt foi designada para a Escola de Comércio Amaro Cavalcanti, onde atuou como professora por três anos, assumindo depois sua direção. Essa escola se tornou seu laboratório, onde pôde experimentar sua proposta para o ensino de línguas inspirada no modelo americano e europeu. Além disso, produziu dois manuais pedagógicos sobre o tema: Mon Petit Univers (méthode vivante) (1934) e 0 Ensino Científico das Línguas Modernas (1935).

No primeiro, estimulada por Venâncio Filho, - outro expressivo militante da educação nova no país, mas da ala não católica -, a autora se antecipava em trazer uma solução a um problema apoiada, em princípio, no diálogo com as experiências de matriz europeia. Intitula sua proposta de "método vivante" - um estágio intermediário entre o método direto e o método científico - e mostra-se atenta aos avanços desse debate na esteira internacional.

Os dois últimos congressos de línguas vivas (de Paris em 1931, e de Roma em 1933), proclamaram, como assentado em bases psicológicas, o método direto; preconizaram, porem, o método propriamente científico como única solução definitiva para os problemas da aprendizagem de uma língua estrangeira. 0 método científico acha-se em franca elaboração. A Holanda apresentou, em 1931, nada menos de 26 processos, inspirados nesse novo espírito. Os estados Unidos mostram-se seriamente empenhados em fixar o vocabulário standard para as diferentes series do ensino de línguas". ${ }^{21}$

É nesse estágio intermediário que a educadora situa seu método naquele momento, a exemplo da iniciativa dos holandeses, e o apresenta em articulação a um

\footnotetext{
${ }^{21}$ SCHMIDT, Maria Junqueira. Mon Petit Univers (Méthode vivante). $4^{\mathrm{a}}$ ed. São Paulo: Companhia Editora Nacional, 1941, p. 3.

Rev. Caminhos da Educação: diálogos, culturas e diversidades, Teresina, v. 2, n. 3, p. 72-91, set./dez. 2020
} 
"Programa Geral embasado na Psicologia e na Pedagogia Genética", adaptado do Programa de Mlle. Kohler (Áustria), que foi apresentado no II Congresso de Línguas Vivas, em 1933.

As características de seu método englobava um conjunto de proposições em consonância com a Psicologia e a Genética assim definidas:

Graduação sistemática da dificuldade na linguagem; emprego de um vocabulário ativo, ensinado por meio de imagens. Matéria apresentada de modo a despertar o interesse (história). Apelo à habilidade manual (desenho, recortes) e, ao gosto estético (música, dansa, declamação, cinema). Aproveitamento da tendência para as coleções (albuns) e do anseio de afirmação da personalidade (dramatizações). Oportunidade para todos os tipos de inteligência, principalmente para os visuais (ilustrações, leituras, ditados, composições cinema). Exercício da atividade manifestada sob a forma de interesse pelos jogos (divertimentos de salão, baralhos educativos, canções, dansas populares, matchs, combinações, disparates, perfis, etc). Desenvolvimento racional da função expressiva (repetição onímoda). Estímulo constante do espírito de iniciativa e de associação. Formação dos hábitos de pesquisa, de atenção, de confiança em si, etc ${ }^{22}$.

Em seu primeiro manual pedagógico, Maria Junqueira não apenas teoriza, mas organiza um programa geral para o ensino de línguas vivas, indica ferramentas pedagógicas e mostra como conduzir as aulas propondo lições e atividades.

Depois de demarcar seu espaço no campo da produção intelectual para a educação, ela se insere no movimento de aproximação Brasil-EUA, empreendido tanto pela Associação Brasileira de Educação quanto pela Secretaria Geral de Instrução Pública do Distrito Federal, dirigida por Anísio Teixeira naquela época. Viaja, em seguida, para aquele país em missão pedagógica a fim de especializar-se e conhecer os avanços feitos em relação ao ensino de línguas vivas ${ }^{23}$. Experiente no

\footnotetext{
${ }^{22}$ SCHMIDT, Maria Junqueira. Mon Petit Univers (Méthode vivante). $4^{\mathrm{a}}$ ed. São Paulo: Companhia Editora Nacional, 1941, p. 4.

${ }^{23}$ Sobre viagens pedagógicas e educadores viajantes, ver Mignot \& Gondra (2007); Viñao Frago (2007), Mignot (2010), Silva (2013), Dantas, Orlando \& Silva (2015).

Rev. Caminhos da Educação: diálogos, culturas e diversidades, Teresina, v. 1, n. 3, p. XXX-XXX, set./dez. 2019
} 
Maria Junqueira Schmidt: uma intelectual católica em diálogo com a Escola Nova

uso das viagens como signos de distinção, em seu retorno, publica um segundo manual, desta vez não mais uma proposta intermediária entre dois métodos, mas uma apropriação do método científico para o ensino de línguas.

Nesse segundo livro, Maria Junqueira nos dá outros indícios de sua interlocução, uma vez que começa a citar diretamente alguns autores dos quais se aproximou mais fortemente, fosse para concordar ou refutar, tais como: Henry C. Morrison, Guy Thomas Buswell, Eugène Dévaud, Walter Fenno Dearborn, Ben Wood, entre outros.

Sobre a leitura silenciosa, defendeu o meio termo, demonstrando conhecer o que pregavam as diferentes correntes:

Não aceitemos, pois, nem a preeminência um tanto demasiada do 'reading methode' de Burswell, Colleman e mesmo de Michael West, nem tampouco os exageros do methodo phonético de Victor, Breymman Breul, Walter e Krause preconizados de certo modo Shweltzer e Simmonot. ${ }^{24}$

Sobre os testes, defendeu o new-type test, proposto por Jacob Greenberg e Ben Wood em 1925, em detrimento do old-type test, sublinhando como ponto positivo o número de palavras raízes presentes no teste, que iam de vocábulos fáceis até os mais difíceis, o que permitia aplicar o mesmo teste a alunos de diferentes níveis. 0 modelo defendido por Ben Wood, segundo a educadora, eliminava a necessidade de atividades secundárias, as quais ela considerava improducentes, como a caligrafia e a tradução. De fato, essa é sua maior crítica ao método americano que, de maneira genérica, ainda recorria à tradução como consequência do uso do "método direto", considerado pela autora como já superado. Valendo-se de uma

\footnotetext{
${ }^{24}$ SCHMIDT, Maria Junqueira. "O ensino científico das línguas modernas. A leitura silenciosa na aprendizagem de um idioma estrangeiro". Correio da Manhã, 18 de maio de 1935, p. 3.

Rev. Caminhos da Educação: diálogos, culturas e diversidades, Teresina, v. 2, n. 3, p. 72-91, set./dez. 2020
} 
formação e posição institucional privilegiada, Maria Junqueira não se absteve de tecer críticas e reformular, como lhe aprouve, os modelos pedagógicos aos quais se expôs. "Corrigidas essas falhas e adaptados ao nosso ambiente, esses testes representarão um meio ideal para a apuração objetiva dos conhecimentos dos alunos no que concerne o francez". 25

Sobre o laboratório de línguas, Maria Junqueira o definiu como um sistematizador de todos os meios auxiliares de ensino dessa disciplina. Comum nas escolas americanas sob o nome de "sala ambiente", a educadora demarca a inauguração desse debate por Pauline Pierson, a partir de um artigo publicado em jornal em 1927, um tema que foi desenvolvido em 1928 por Charles Hart Handschin e retomado no Congresso de Línguas Vivas (realizado em Paris em 1931 e Roma em 1933). Esses debates inaugurais se desdobraram nas experiências de ensino de línguas vivas sob o nome de "laboratório". Na esteira desses debates, ela organizou o primeiro laboratório de línguas vivas do Brasil, em abril de 1934, na Escola de Comércio Amaro Cavalcanti, onde era diretora. ${ }^{26}$

No relatório em que se remete a essa experiência, observada de forma entusiástica nos EUA, Maria Junqueira destacou o uso de discos falados, jogos (faz remissão a um de seus livros - Heure joyeuse - em que já utilizava esse auxiliar de ensino), baralhos, fichas, cadernos ilustrados, álbuns, coleções de gravuras, desenhos, quadros murais, leitura suplementar e canto, dramatização, clube de línguas. Ressaltou, no entanto, dois pontos frágeis nesse processo de modernização da educação americana: a ausência do uso de filmes como auxiliares de ensino - o que no Brasil já vinha sendo entusiasticamente estimulado - assim como a escassez ou nível muito elementar das aulas pelo rádio. Destacou a preocupação das escolas em ensinar não apenas a língua, mas a civilização do povo cuja língua se estudava, ideia que embasava a proposta da "sala ambiente" como uma forma de imersão na cultura do outro país. Adotada em quase todas as escolas americanas, a ambiência era suscitada por cartazes de turismo, produtos típicos, selos, álbuns de vistas,

\footnotetext{
${ }^{25}$ SCHMIDT, Maria Junqueira. O ensino científico das línguas modernas. Os testes e o ensino de idiomas. Correio da Manhã, 29 de maio de 1935, p. 2.

${ }^{26}$. LABORATORIO DE LINGUAS VIVAS. A proxima inauguração na Escola Amaro Cavalcanti. Correio da Manhã, 29 mars 1934, p. 6.

Rev. Caminhos da Educação: diálogos, culturas e diversidades, Teresina, v. 1, n. 3, p. XxX-Xxx, set./dez. 2019
} 
Maria Junqueira Schmidt: uma intelectual católica em diálogo com a Escola Nova

livros, revistas, folhetos e jornais do país abordado, também utilizados nas atividades de leitura suplementar. ${ }^{27}$

De modo geral, no âmbito do método científico, Maria Junqueira destacou a importância dada à leitura silenciosa, aos testes e ao laboratório, com ênfase neste último. Ela se apoiava na literatura americana produzida, sobretudo, a partir de experiências realizadas nas escolas dos EUA, articuladas às experiências e à literatura europeia.

Embora salientasse que essa iniciativa já vinha sendo empreendida na Europa, inclusive com este nome, foi a partir da imersão pedagógica em terras norteamericanas que a educadora impulsionou a experiência na Escola de Comércio Amaro Cavalcanti fundamentada no método científico, demarcando seu pioneirismo nesse domínio no Brasil.

\section{Considerações Finais}

A militância de Maria Junqueira Schmidt em prol da renovação do ensino brasileiro e a aproximação tanto das contribuições advindas da Europa quanto dos EUA nos permite pensar três problemas historiográficos com os quais temos nos deparado nos últimos anos: os processos de circulação e apropriação dos modelos pedagógicos que se empreendeu sob a bandeira da Escola Nova; a atuação de intelectuais católicos em frentes de ação pouco exploradas como uma forma de demarcação de um lugar na renovação do campo educacional brasileiro; a participação das mulheres de diferentes grupos, como intelectuais, na militância por uma escola nova em meio à arena política de disputas que se travou no campo educacional brasileiro.

\footnotetext{
${ }^{27}$ SCHMIDT, Maria Junqueira. O ensino científico das línguas modernas. O laboratório de línguas nos Estados Unidos. Correio da Manhã, 08 de junho de 1935, p. 2. Rev. Caminhos da Educação: diálogos, culturas e diversidades, Teresina, v. 2, n. 3, p. 72-91, set./dez. 2020
} 
De acordo com Azzi (2008, p. 109), no Brasil, “durante a primeira metade do século XX, a Igreja teve uma influência primordial na área do ensino médio". Muito embora essa ênfase tenha sido dada à rede de escolas particulares que fundou, é preciso atentar para os diferentes modos pelos quais também se fez presente na escola pública, dentre eles, pela atuação militante de seus intelectuais. Em ambas as frentes, buscava-se formar uma juventude apta a assumir postos de direção na sociedade, formada dentro dos princípios da religião e da moral católica.

Foi dentro dessa segunda linha de ação tática que a educadora Maria Junqueira Schmidt inseriu-se e afirmou-se no campo da produção intelectual do país, tendo a educação como seu lugar privilegiado de fala. Atuante e forte defensora da pedagogia nova alinhada ao catolicismo, é possível perceber traços da cultura católica em seus discursos e em todos os seus livros. Além de abordar a temática proposta, seus livros faziam emergir lições de moral, doutrina e valores do catolicismo, aliando de forma quase "natural" ciência e fé, a partir da educação, como elementos da aliança possível entre tradição e modernidade.

\section{Referências Bibliográficas}

AZZI, Riolando. A Igreja Católica na formação da sociedade brasileira. Aparecida, SP: Editora Santuário, 2008.

DALLABRIDA, Norberto; FRANCO, José Eduardo. Dossiê: Escola Nova Católica na Europa e no Brasil. Educação Unisinos, v. 22, n. 3, jul./set. 2018.

FREITAS, I. Uma versão católica para a história do Brasil nos anos 30. Educação e filosofia, 21(42), p. 251-272, 2008.

MIGNOT, A. C. Viajar para legitimar: Armanda Álvaro Alberto na comissão de Intercâmbio Brasil-Uruguai (1931). Revista Brasileira de História da Educação, n. 22, p. 43-64, 2010.

MIGNOT, A. C.; GONDRA, J. G. (org.). Viagens Pedagógicas. São Paulo: Cortez, 2007.

ORLANDO, E. A. "A Bandeira e a Cruz": caminhos da trajetória intelectual da educadora Maria Junqueira Schmidt. Educar em Revista, 33(65), p. 103-118, 2017a.

ORLANDO, E. A. Maria Junqueira Schmidt e os caminhos de uma trajetória intelectual pela palavra impressa. In: E. A. Orlando (org.). Histórias da Educação Católica no Brasil e em Portugal. Curitiba, PR: Appris, 2017b. p. 119-140.

Rev. Caminhos da Educação: diálogos, culturas e diversidades, Teresina, v. 1, n. 3, p. xxx-xxx, set./dez. 2019 
Maria Junqueira Schmidt: uma intelectual católica em diálogo com a Escola Nova

ORLANDO, Evelyn de Almeida. Quando o mundo cabe na bagagem: as experiências de formação e distinção de Maria Junqueira Schmidt. In: SILVA, Alexandra Lima da; ORLANDO, Evelyn de Almeida; DANTAS, Maria José. Mulheres em trânsito: intercâmbios, formação docente, circulação de saberes e práticas pedagógicas, Curitiba: Editora CRV, 2015. p. 209-225.

ORLANDO, E. de A. Por uma civilização cristã: a coleção Monsenhor Álvaro Negromonte e a Pedagogia do Catecismo (1937-1965). 2008. 380 f. Dissertação (Mestrado em Educação) - Universidade Federal de Sergipe, São Cristóvão, 2008.

PRACHUM, Bianca Neves. Educação e catolicismo: a construção de um modelo de professor e as apropriações católicas da Escola Nova a partir de Everardo Beckheuser (1928-1946). 2019. Dissertação (Mestrado em Educação) Universidade Estadual de Ponta Grossa, Ponta Grossa, 2019.

SGARBI, A. D. Igreja, educação e modernidade na década de 30: escolanovismo católico, construído na CCBE e divulgação pela Revista Brasileira de Pedagogia. Dissertação (Mestrado em Educação) - Pontifícia Universidade Católica de São Paulo, São Paulo, 1997.

SILVA, Alexandra Lima da. Ideias em movimento: viagens como horizonte na historiografia da educação. Roteiro, Joaçaba, Ed. Especial, p. 109-126, 2013.

SILVA, Alexandra Lima da; ORLANDO, Evelyn de Almeida; DANTAS, Maria José. Mulheres em trânsito: intercâmbios, formação docente, circulação de saberes e práticas pedagógicas. Curitiba: Editora CRV, 2015.

SILVA, G. J. O Batismo de Clio: catolicismo social e História em Jonathas Serrano (1908-1931). Dissertação (Mestrado em Educação) - Universidade Federal de São João del Rei, São João del Rei, 2011.

SKRUSINSKI, J. G. G. (2018). "Nós somos a história": o projeto de educação das famílias nas obras de Maria Junqueira Schmidt. Dissertação (Mestrado em Educação) - Pontifícia Universidade Católica do Paraná, Curitiba, 2018.

SKALINSKI JUNIOR, O. Alceu Amoroso Lima e a Renovação da Pedagogia Católica no Brasil (1928-1945): uma proposta de espírito católico e corpo secular. Curitiba: Editora CRV, 2015.

VIÑAO FRAGO, A. Viajes que educan. In: MIGNOT, A. C.; GONDRA, J. G. (org.). Viagens Pedagógicas. São Paulo: Cortez, 2007. p. 15-38.

Rev. Caminhos da Educação: diálogos, culturas e diversidades, Teresina, v. 2, n. 3, p. 72-91, set./dez. 2020 
Fontes:

CORREIO DA MANHÃ. Novo methodo para o ensino de linguas "MÉTHODE VIVANTE". Correio da Manhã, 24 fevereiro 1934, p. 2.

DIÁRIO DE NOTÍCIAS. Diário de Notícias, Rio de Janeiro, 20 junho 1933, p. 6.

DIÁRIO DE NOTÍCIAS. Maria Junqueira Schmidt. Diário de Notícias, Rio de Janeiro, 8 abril 1934, p. 21.

DIÁRIO DE NOTÍCIAS. Livros bons para as crianças - A primeira reunião, hontem, da Commissão de Literatura Infantil, no Ministerio da Educação. Diário de Notícias, Rio de Janeiro, $1^{\circ}$ maio 1936, p. 2.

DIÁRIO DE NOTÍCIAS. Designada uma commissão para compra de livros escolares. Diário de Notícias, Rio de Janeiro, 14 agosto 1938, p. 2.

DIÁRIO DE NOTÍCIAS. Para organização dos programas do curso ginasial - Uma portaria do ministro da Educação estabelecendo normas para os trabalhos da comissão encarregada. Diário de Notícias, Rio de Janeiro, 28 abril 1942, p. 6.

DIÁRIO DE NOTÍCIAS. Instituida a comissão de estudo das diretrizes e bases da educação. Diário de Notícias, Rio de Janeiro, 8 abril 1947, p. 6.

JORNAL DO BRASIL. Jornal do Brasil, Rio de Janeiro, 17 fevereiro 1929, p. 16.

O ESTADO DE SÃO PAULO. Leituras e conferências - Salão do conservatório: "Conferência pedagógica" pela senhorita Maria Junqueira Schmidt". O Estado de São Paulo, São Paulo, 2 dezembro 1920, p. 10.

SCHMIDT, Maria Junqueira. A educação da criança na palavra de uma conferencista. Jornal A.B.C., Rio de Janeiro, 18 juilho 1925, p. 9.

SCHMIDT, Maria Junqueira. ESCOLA ACTIVA. Metodo novo para o ensino das línguas vivas. Correio da Manhã, Rio de Janeiro, 19 julho 1929, p. 7.

SCHMIDT, Maria Junqueira. 0 ensino científico das línguas modernas. A leitura silenciosa na aprendizagem de um idioma estrangeiro. Correio da Manhã, Rio de Janeiro, 18 maio 1935, p. 2.

SCHMIDT, Maria Junqueira. 0 ensino científico das línguas modernas. Os testes e o ensino de idiomas. Correio da Manhã, Rio de Janeiro, 29 maio 1935, p. 2.

SCHMIDT, Maria Junqueira. 0 ensino científico das línguas modernas. 0 laboratório de línguas nos Estados Unidos. Correio da Manhã, Rio de Janeiro, 8 junho 1935, p. 2. 
Maria Junqueira Schmidt: uma intelectual católica em diálogo com a Escola Nova

RECEBIDO: 01/07/2020

APROVADO:03/08/ 2020
RECEIVED: $01 / 07 / 2020$

APPROVED: 03/08/ 2020
RECIBIDO: 01/07/ 2020

APROBADO: 03/08/ 2020

Rev. Caminhos da Educação: diálogos, culturas e diversidades, Teresina, v. 2, n. 3, p. 72-91, set./dez. 2020 